\title{
La participación de la tropa en la sublevación del Palmar
}

\author{
Francisco Varo Montilla
}

\section{RESUMEN ABSTRACT}

\begin{abstract}
El 8 de julio de 1819 intentó pronunciarse parte del Ejercito expedicionario de Ultramar que mandaba el conde de La Bisbal. Para que la empresa tuviese éxito se aprovechó el descontento de la tropa con el embarque y se realizó una labor previa de atracción y de adoctrinamiento de estas clases para que apoyasen el levantamiento junto a sus oficiales liberales. Parte de la dinámica de este proceso de atracción es la que se expone en este trabajo.
\end{abstract}

\section{PALABRAS CLAVE Pronunciamiento, sublevación, levantamiento, liberalismo, Antiguo Régimen, Ejército, sociedades secretas, conjura, O'Dónnell, Sarsfield, O'Daly, Puerto de Santa María.}

On July 8th, 1819 part of the expeditionary Army of Overseas that was led by the count of La Bisbal, tried to rebel. In order that the company had success it was taken advantage of the dissatisfaction of the troop with the shipment and there was realized a previous labour of attraction and of indoctrination of these classes in order to leaning the raising together with theirs liberal officials. Part of the dynamics of this process of attraction is the one that is exposed in this work.

\section{KEY WORDS}

Pronouncement, revolt, raising, liberalism, Old Regime, Army, secret societies, conspiracy, O'Dónnell, Sarsfield, O'Daly, Port of Santa Maria. 


\section{INTRODUCCIÓN}

Se ha escrito mucho sobre el pronunciamiento del 1 de enero de 1820 por su consabida trascendencia. También se conocen algunas de las acciones previas al levantamiento del Ejército expedicionario de Ultramar, quiénes fueron sus protagonistas más destacados o la intervención de varios cuerpos. Por otra parte, en general, está claro el motivo que llevó a la sublevación: reinstaurar un gobierno constitucional. Pero llegados a este punto, faltaba conocer la dinámica interna de todo aquel asunto. Debido a ello, por más que sean notorios los grandes personajes, resultan un tanto desconocidos quienes se mantuvieron en los escalones intermedios y bajos, cuya labor fue absolutamente necesaria para dar cohesión al conjunto de órganos que se usaron dentro de una trama que hizo posible la sublevación.

Por ello, este trabajo penetrará en uno de los elementos que intervino para hacer posible el corto advenimiento constitucional: el propio Ejército expedicionario. Intentará llegar a las motivaciones de aquéllos sin cuya colaboración no hubiese sido posible el levantamiento. Se procurará, también, explicar la paradójica cooperación entre los individuos de clases militares diferentes para llegar a aquel resultado, habida cuenta de lo que había ocurrido en intentos anteriores.

En el momento decisivo de un pronunciamiento: el rompimiento, a pesar de la supuesta perfección de los planes para conseguir unos objetivos inmediatos, de los preparativos para llevarlos a buen término, de tener un general de prestigio el frente, del apoyo de cierta trama conspirativa y de la supuesta bondad del programa político, la experiencia había demostrado que, era fundamental la adhesión de la tropa, ya que su falta de apoyo había sido la causa del fracaso en intentos anteriores, como quedó demostrado con Espoz y Mina, Porlier o Lacy ${ }^{1}$.

El acercamiento a esta clase militar en la época podría traslucir, entre otras cosas, si eran conscientes de la repercusión posterior de sus actos. Por ello, este estudio se centrará principalmente en los soldados que debían devolver a Fernando VII la soberanía de los territorios rebeldes de América. Un colectivo cuya percepción de la materia de-

1 Se ha tomado el pronunciamiento en su definición, ya clásica, de José Luis Comellas: «una forma de golpe militar asestado contra el poder para introducir en él reformas políticas, propio de la Historia española del siglo xix", COMElLAS, José Luis, Los primeros pronunciamientos en España 1814-1820, Consejo Superior de Investigaciones Científicas, Escuela de Historia Moderna, Madrid, 1958 
pendía en gran medida de las lecciones que recibían de algunos de sus jefes y oficiales, de quienes podían considerar sus líderes natos. En esta tesitura, las personas difícilmente se podían sustraer de la educación que habían recibido y aquellos se encontraban dentro de una sociedad general estamental y dentro de esta de otra militar, con una jerarquía estricta.

Los militares liberales de 1819, año en el que se centra el trabajo, podían tener la preparación necesaria para adoptar esta ideología, convencidos de su conveniencia. Pero, ¿había liberales entre la tropa? Muchos de esta clase apoyaron la sublevación, no ya la de Riego, sino los diversos intentos que se produjeron en 1819. Esto era nuevo, hasta entonces no se había producido tal perseverancia. Esta clase debió romper con sus principios para estar al lado de unos revolucionarios, cuyas ideas y cuyo programa probablemente no entendiesen, para actuar contra la sagrada figura del monarca más deseado. La tropa tuvo que enfrentarse a la voluntad del rey para apoyar a los liberales y, probablemente, ni quería lo primero ni entendería correctamente qué pretendían los otros. Así que con este planteamiento se intentará explicar la cuestión en las páginas que siguen.

Como es sabido, en 1815 se mandó formar el Ejército expedicionario de Ultramar. La reunión de tan extraordinaria fuerza respecto a los recursos existentes, supuso un esfuerzo extraordinario y nunca se llegó a completar con los efectivos previstos ${ }^{2}$. El conocimiento que se tiene del mismo es escaso, sólo se ha dado el nombre y ubicación temporal de algunas de sus unidades ${ }^{3}$. Es interesante saber esta cuestión porque fue una fuerza que se politizó y se polarizó según la ideología predominante en sus cuerpos ${ }^{4}$. Estos eran unidades militares jerarquizadas y con cierta independencia, lo que tendrá un gran peso en los acontecimientos que se produjeron.

2 Vid. Artola, Miguel, La España de Fernando VII, ed. Espasa, Madrid, 1999, pág. 501.

3 Ramón Santillan en sus memorias y Jose Luis Comellas en la obra citada, han dado la ubicación del algunas unidades del Ejército, pero hay que tener en cuenta que esta lo era por tiempo limitado. Vid. Comellas, José Luis, o. c., pág. 322, y, SANTILLÁN, Ramón, Memorias (1808-1816), ed. Tecnos, 1996, Madrid, pág. 91. Según el General en Jefe del Ejército, para mantener ocupada a la tropa y evitar que pensase en revolución, sometió a los batallones a continuos cambios de Cantón. Escrito del conde de La Bisbal a los fiscales, Madrid, 12 de octubre de 1819, Archivo General Militar (en adelante AGM), Sección 9. ${ }^{a}$, Legajo 11 , Cuaderno $3 .^{\circ}$, folio 482.

4 "Cuerpo" sería un regimiento, un batallón o cualquier otra unidad que se caracterizara por tener entidad propia, con un jefe común y con posibilidades de hacer vida por sí misma. Así, sería cuerpo un batallón independiente, pero no un batallón que estuviese integrado en un regimiento, ya que en este caso, sería esta última unidad la que se denominara cuerpo. 
Que se estudien aquí las distintas Armas, no responde a un mero conocimiento curioso, sino que dependiendo de la que se trate, existirá una mayor o menor propensión para sumarse a la sublevación. El Arma de infantería tenía la mayor cantidad de hombres, su unidad básica era el batallón. Le seguía la caballería menos numerosa pero más potente, distribuida en escuadrones que formaban regimientos. En tercer lugar, la escasa y mal dotada artillería con dos unidades diferentes una a pie y otra montada. Y por último, los zapadores con un sólo batallón. La mayoría de las unidades mencionadas formaban cuerpos, que se movían por diferentes cantones próximos a la zona de embarque periódicamente, estableciéndose una rotación por los cuarteles y campamentos de las diferentas ciudades ${ }^{5}$. Estos movimientos dieron lugar a unas curiosas y nada casuales agrupaciones de unidades los días inmediatos al 8 de julio de 1819.

Tomando este año como referencia, tenemos que en marzo la artillería estaba al completo por el levantamiento, a ella pertenecían muchos de los más importantes conspiradores. Por el contrario, ya en el mes de julio, los zapadores no quisieron intervenir. Probablemente hubiese algunos oficiales sueltos que perteneciesen a la conjura, pero sin posibilidad de arrastrar a su unidad siendo una minoría. La infantería estaba dividida, aunque una mayoría de batallones completos optó por la sublevación y, en los que no fue así, había multitud de oficiales dispuestos a unirse cuando se produjese; de hecho, de un total de dieciséis, en julio, fueron ocho los que intentaron pronunciarse y de otro se tenían fundadas sospechas de que estaba por la sublevación. La caballería se encontraba en las mismas circunstancias que la infantería pero la proporción era inversa. De los cuatro regimientos dos estuvieron en julio netamente al lado del rey y en los otros dos se sospechaba que ya había penetrado la conspiración.

Los cuerpos del Ejército expedicionario, sus jefes y su situación geográfica el 6 de julio de 1819 están en la tabla que va a continuación. En ella no se tienen en cuenta los Depósitos de las distintas Armas en los que se concentraban e instruían hasta pasar a las unidades los recientemente reclutados.

5 De los dieciséis batallones que he encontrado pertenecientes al Ejército expedicionario en 1819, sólo dos de ellos consta que formasen un regimiento, el de Aragón. 


\section{Ejército Expedicionario de Ultramar 6 de julio de 1819}

\begin{tabular}{|c|c|c|}
\hline Cuerpo & Jefe de Unidad & Situación geográfica \\
\hline Batallón $1 .{ }^{\circ}$ Aragón & Coronel Antonio Roten & Puerto Santa María \\
\hline Batallón 2. Aragón & Coronel Antonio Roten & Puerto Santa María \\
\hline Batalión Ligero Canarias & Brig. Demetrio O’Daly & Puerto Santa María \\
\hline Batallón 2. ${ }^{\circ}$ Rey & Coronel Salvador Hes & Cádiz \\
\hline Batallón $2 .^{\circ}$ Soria & Coronel Salvador Díaz Berrio & Puerto Santa María \\
\hline Batallón $2 .^{\circ}$ Valencia & Coronel Sebastián Velasco & Puerto Santa María \\
\hline Batallón 2. ${ }^{\circ}$ Princesa & Teniente Coronel Joaquín Gayón & Cádiz \\
\hline Batallón 2. Málaga & No se ha encontrado & San Lúcar Barrameda \\
\hline Batallón $1 .^{\circ}$ Cataluña & Coronel Antonio Quiroga & Puerto Santa María \\
\hline Batallón Guías del Gral. & Cap. Ramón María Labra & Puerto Santa María \\
\hline Batallón $2 .^{\circ}$ Cataluña & Coronel Rodríguez Callejas & San Fernando \\
\hline Batallón $2 .^{\circ}$ Asturias & $\begin{array}{l}\text { Teniente Coronel Santos } \\
\text { San Miguel }\end{array}$ & Puerto Santa María \\
\hline Batallón Príncipe & Coronel José Cadaval & Cádiz \\
\hline Batallón América & Coronel Pedro Guerra & Cádiz \\
\hline Batallón Guadalajara & Coronel Hierro & Cádiz \\
\hline Batallón Sevilla & No se ha encontrado & San Lúcar Barrameda \\
\hline $\begin{array}{l}\text { Regimiento Dragones } \\
\text { del Rey }\end{array}$ & Coronel José González Anleo & Puerto Santa María \\
\hline $\begin{array}{l}\text { Regimiento Dragones } \\
\text { del General }\end{array}$ & Coronel Juan Dewitte & Jerez de la Frontera \\
\hline Regimiento Farnesio & Coronel Andrés Briones & Jerez de la Frontera \\
\hline Regimiento Alcántara & No se ha encontrado & Jerez de la Frontera \\
\hline Brigada Artillería a pie & Coronel Joaquín Ponte & Puerto Santa María \\
\hline Escuadrón Artillería & Coronel Miguel López Baños & Puerto Real \\
\hline Batallón Zapadores & Coronel Sánchez & Puerto Real \\
\hline
\end{tabular}

En cuanto a la conspiración, en marzo o abril de 1819 ya había penetrado en el Ejército expedicionario. Pudo ser a través de las "logias" que existían en algunos de los cuerpos. Se sabe que desde Madrid llegaban cartas a los oficiales del Ejército cuyos remitentes estaban siendo vigilados o investigados por sospecharse que pertenecían a sociedades secretas. Además, desde la dirección de la conjura se había destacado a un agente, el coronel Bartolomé Gutiérrez, para servir de contacto con los generales del Ejército, que debían ponerse al frente de la sublevación. Éste probablemente tuviese dos lugartenientes en los militares de las planas 
mayores, Felipe Arco Agüero y José Grases. Y, teóricamente, encabezándolo todo debia encontrarse el General en Jefe conde de La Bisbal.

Según lo visto, se puede componer fácilmente la siguiente estructura: en primer lugar, había unas sociedades secretas o como ellos las denominaban, Juntas «masónicas», que dirigían políticamente la conspiración y tenían su enlace en Gutiérrez. En segundo lugar, había otra serie de Juntas establecidas en la zona de Cádiz que apoyaron al Ejército con infraestructuras, financiación y logística, en las que se integraban algunos militares pertenecientes a las «logias» de las unidades. $Y$ finalmente, estaban las mencionadas «logias» de los cuerpos que formaban sus Juntas a las que pertenecían sólo los oficiales. Es probable que sobre enero de 1819, después de fallar otras posibilidades, a la dirección de la conspiración no le quedase más remedio que usar al Ejército expedicionario para llevar a cabo sus propósitos ${ }^{6}$. Una vez esbozadas tanto las características del Ejército expedicionario como de la conspiración del Palmar, será fácil seguir los pasos que dieron los rebeldes para hacer que la tropa participase en la sublevación ${ }^{7}$.

\section{ATRACCIÓN DE LA TROPA A LA SUBLEVACIÓN Y LA DELACIÓN DE LA CONJURA}

Se conocen las maniobras de los conspiradores para atraer a la tropa de los cuerpos expedicionarios, porque se denunció a un grupo de sargentos implicados en el asunto. Para esclarecerlo, se abrió una sumaria investigación que pasó a formar parte de la causa abierta por los acontecimientos del 8 de julio. Llevó las actuaciones un Juez-Fiscal militar de uno de los batallones que reprimieron la sublevación, quien probablemente no compartiese las ideas de los rebeldes, y por ello hizo gala de una eficiencia inaudita. La sumaria se desarrolló y se cerró con sus conclusiones en un plazo de tiempo extraordinariamente corto si se compara con el desarrollo de la causa principal.

\footnotetext{
6 Esta es la que he denominado «La conspiración del Palmar», que ha sido estudiada por primera vez en mi trabajo de investigación que lleva aquel título. Por otro lado, otro reciente estudio parece que enlaza la conspiración del corone! Vidal, en Valencia, con esta del Palmar, aunque el medio que usaron en una y otra ocasión para cambiar el régimen es diferente. Vid. MoRANGE, Claude, El programa político de la Conspiración de 1819 , Trienio, n. ${ }^{\circ} 39$, Mayo 2002, pp. $31-46$

7 Parte de lo dicho ha sido ya publicado en soporte informático (CD): Vid. VARO MONTILLA, Francisco, Liberalísmo Revolucionario y la gestación de un régimen constitucional: 1819 La Conspiración del Palmar, comunicación al congreso internacional Orígenes del Liberalismo, ed. Universidad de Salamanca, Salamanca, 2002.
} 
El fiscal Cristóbal Krucker O'Dónnell fue nombrado el 17 de julio de 1819. Para que diesen comienzo las diligencias, se le envió el parte que denunciaba la actuación de los acusados, la relación nominal de éstos y el lugar donde se encontraban presos e incomunicados. Inmediatamente comenzaron los interrogatorios, en primer lugar, de los denunciantes, después de sus testigos, todos ellos partidarios del gobierno del rey y, por tanto, contrarios a las tesis de los rebeldes. En sus manifestaciones no se advierten demasiadas ambigüedades y expusieron al fiscal todo aquello que habían visto u oído, detalladamente, relacionado con lo que se les preguntaba. Por otro lado, a los acusados no les quedó más remedio que intentar hacer creer que no sabían nada de las cuestiones sobre las que eran interrogados. Las preguntas se basaban en gran medida en lo que ya se conocía y, por tanto, abundaban en pormenores. El 23 de julio de 1819 la sumaria que instruyó Krucker había concluido y fue enviada al fiscal que llevaba la causa del Palmar, por la evidente relación entre una y otra ${ }^{8}$.

Volviendo atrás en el tiempo, hay que hacer notar que la denuncia de lo que ocurría entre la tropa tuvo verdadera importancia y adquirió un carácter dramático para sus protagonistas. La delación llegó al gobierno, que se enteró de lo que ocurría en la zona de Cádiz y en el Ejército expedicionario por fuentes diferentes al conde de La Bisbal. Además, la información llegó a la Corte por cauces poco usuales y debía diferir de la que enviaba el Capitán General de Andalucía, el mismo conde de La Bisbal, por lo que hizo saltar la alarma como lo demuestra la actuación posterior del gobierno y el rey.

Del análisis de la documentación se desprende que el primer paso para conseguir la adhesión de la tropa fue atraer, en un principio, a los de mayor graduación: los sargentos primeros y sargentos de las compañías que podían influir sobre los demás. Esto ocurría ya en el mes de junio en el batallón primero de Cataluña. El coronel Antonio Quiroga realizaba reuniones en su propia casa en Cádiz con individuos de aquellas clases. No se sabe ciertamente qué se trataba allí, pero se puede conjeturar que servirían para aleccionar a los asistentes, armarles de argumentos que exponer a sus subordinados inmediatos y preparar el levantamiento en sus respectivas Compañías ${ }^{9}$. Los sargentos convencidos intentaban después

8 Oficio de Cristóbal Krucker O'Dónnell remitiendo al fiscal Gaspar Blanco una sumaria instruida en Cádiz, 23 de julio de 1819, AGM, Sección 9." Legajo 11, Sumaria separada contra el sargento primero José Cortat, folio 1.

9 De casa de Quiroga salían por las tardes los reunidos conversando entre sí discretamente, situación inusual, que despertó la curiosidad de alguno que no participaba y que, evidentemente, no quería adherirse a la sublevación, por lo que una vez fracasada manifestó sus sospechas. Declaración del sargento segundo Antonio Vázquez. Cádiz, 20 de julio de 1819, lbídem, pág. 177. 
atraer a los indecisos, mostrándoles las ventajas que les proporcionaria un régimen constitucional. Si no lo conseguían les amenazaban con el destierro o con penas mayores una vez triunfase el golpe, lo que daban por seguro. $Y$, de persistir la negativa, les separaban del batallón con el pretexto de realizar un servicio en algún lugar alejado del punto donde se iba a producir el rompimiento y del lugar donde se encontraban las autoridades del Ejército para que no interfiriesen ${ }^{10}$.

Después, los sargentos se dirigían a los soldados. En la primera compañía del primero de Cataluña, parece que uno de aquéllos cometió una gran imprudencia. Seguramente, envalentonado por la situación de extrema impunidad en la que se encontraban los partidarios de la sublevación dentro del batallón y alertado del inminente levantamiento de los cuerpos rebeldes. Éste, de nombre José Cortat, se atrevió a manifestar ante toda la compañia que se iba a producir en pocos días el movimiento revolucionario por la Constitución, entre otras descompasadas e inoportunas palabras. La noche del 27 al 28 de junio, para convencer a sus compañeros de que se sumasen al levantamiento, comenzó a denostar al gobierno del rey y alabar al constitucional. A pesar de todo, ni Cortat decía nada nuevo, ni sus compañeros lo escucharon por primera vez en aquella ocasión, pues lo que se trató era habitual en conversaciones particulares. Lo sorprendente fue la desmedida publicidad que se dio aquella noche, ante un auditorio numeroso, como si de un mitin se tratase ${ }^{11}$.

Enire otras cosas, Cortat pronosticó una serie de medidas que se debían tomar cuando lo revolucionarios llegasen al gobierno y que coincidían con las conocidas del programa liberal. Unas afectaban a la Iglesia e instituciones afines: extinción del clero regular, cierre de conventos y pago de un sueldo por parte del Estado a los afectados por estas medidas; traspaso a la titularidad de la Nación de las propiedades de los conventos que se cerrasen; y supresión de la Inquisición, institución que calificaba de injusta, irregular y secuestradora de personas de las que nunca más se llegaba a saber.

10 El «destierro», en este caso, suponía la separación del implicado de su unidad a otro lugar diferente del que se encontraba o enviarle fuera de su residencia habitual, lo que se consideraba una pena suficientemente dura. Uno de los que salieron del batalón de Quiroga denunció su situación: Declaración del sargento segundo Benito Brunet. Cádiz, 17 de julio de 1819, ibídem, pág. 164.

11 El discurso de Cortat no era desconocido como mostraron los interrogatorios, pregunta: «Si alguna otra noche Cortat tuvo alguna otra conversación que indujese al desorden», respuesta: «Alguna otra vez si que le ha oído, pero nunca con la publicidad de aquella noche». Declaración de Andrés García. Ibídem. pág. 166. 
La exposición de estos tres puntos, en algunos casos, más que atraer partidarios consiguió el efecto contrario, pues los pasivos interlocutores interpretaron que los revolucionarios perseguían «el fin de la religión», y muchos se opusieron por ello. También vaticinó la eliminación de los «empleados de rentas superfluos" cuyos sueldos pasarian al Tesoro público. Este punto no es claro y no se sabe con certeza a quiénes se podía referir exactamente.

Además, sutilmente estableció una comparación entre el gobierno personalista y opresor que representaba Fernando VII con otro constitucional. Establecía una diferencia esencial entre ellos, pues le daba más valor al principio de autoridad basado en el conocimiento que al basado en la coacción y en la inmunidad. El primero lo representaba un régimen constitucional, en el que había mayores posibilidades de participación ciudadana. La Constitución se presentaba como una ley hecha por «hombres doctos", por lo que, a pesar de la resistencia de parte de la sociedad a seguirla, finalmente, la razón debería imponerse y los más reacios acabarían convencidos de la bondad del sistema en que imperase. No es difícil intuir a qué régimen se refería en la segunda de las afirmaciones.

Concretando más, manifestó las ventajas que obtendría la tropa si se reinstauraba la Constitución. Con ellas cubría todas sus expectativas, la oferta estaba bien planificada. Quienes luchasen por el restablecimiento de la Constitución, tendrían los medios necesarios para conseguir su estabilidad económica en el futuro régimen. Parte del ofrecimiento era, evidentemente, que ya no embarcarían hacía América, lo que cubría las expectativas más deseadas de la mayoría. En segundo lugar, que obtendrían aumentos de sueldo y la nueva ley permitiría que los retiros que se produjesen se realizaran en condiciones que permitiesen asegurar el futuro. $Y$ finalmente, por si no funcionase la prédica con que intentaba atraer a sus compañeros ni la seducción de los incentivos que les ofrecía, usó también amenazas que iban desde el castigo corporal, pasando por el destierro, hasta la muerte. Con ello pretendía intimidar a su auditorio y conseguir que los contrarios o los indecisos, por temor a los revolucionarios, no se opusiesen a la sublevación.

De cualquier manera, la actitud de Cortat influyó profundamente en sus compañeros, que permanecieron casi todos silenciosos. Aunque, para algunos de ellos, una cosa era aceptar indiferentemente una sublevación contra el embarque y otra aprovechar aquel levantamiento para cambiar el régimen forzando al rey. De ahí la insistencia con que los conjurados actuaban sobre la tropa mediante individuos de la misma clase, con los mismos intereses. Lo que finalmente pudo decantar muchas opiniones fue el 
descubrimiento de que aquella «revolución» era promovida y la mantenía, en primera instancia, el comandante de su batallón, Quiroga. Éste, por su posición, tenía un considerable poder intimidatorio y podía actuar sobre los contrarios o irresolutos. Y, el más importante, que a la cabeza de la trama se encontraba el mismísimo General en Jefe del Ejército expedicionario de Ultramar conde de La Bisbal, lo que debió acentuar el miedo en unos o la confianza en la empresa en la mayoría de los presentes, dado el ascendiente y el poder del personaje ${ }^{12}$.

La mañana del día 28 de junio un sargento y dos cabos primeros opuestos a Cortat pusieron en conocimiento del oficial que mandaba la compañía, el teniente Juan José Carrera y del segundo de la misma, el subteniente José Antonio Santos, lo acontecido la noche anterior. Dicho sargento se había enfrentado a Cortat ante el resto de la unidad defendiendo las tesis contrarias y por orden de Quiroga era separado de su compañía para que no interfiriese. Esta acción no fue inocua, pues infringía las normas del Ejército injustificadamente, y constituyó una pista para descubrir la actuación conspirativa frente a una futura investigación. La práctica de separar de los batallones comprometidos a personas desafectas a la sublevación mediante algún argumento medianamente aceptable, seguramente se había aplicado en otras ocasiones. De hecho, habría afectado a otros oficiales de quienes se decía que eran partidarios del rey, uno de ellos el segundo comandante del batallón ${ }^{13}$.

Los dos oficiales ante quienes se había denunciado la conducta de Cortat decidieron elevarla a instancias superiores intentando salvaguardar, a la vez, su posición y sus propias vidas. Pero, ¿en qué autoridad del Ejército podían confiar?. Ignoraban que el general Sarsfield estaba formando un partido contrarrevolucionario, como se verá más adelante. Las dificultades que conllevaba la delación eran enormes, temiendo la impli-

12 Sobre las opiniones de Cortat y la reacción de sus compañeros hay varios testimonios, entre ellos: Declaración del teniente José Antonio Santos, Cádiz, 17 de julio de 1819, ibídem, pág. 162. Declaración del soldado Juan Velasco, Cádiz, 17 de Julio de 1819, ibídem, pág. 167. Declaración de Baltasar Muñoz, Cádiz, 17 de julio de 1819, ibídem, pág. 168.

13 Respecto a la delación: "El declarante ante la gravedad de lo que había oído se confió al teniente de su Compañía Juan José Carrera y al subteniente Antonio Santos, en quienes confiaba y sabía que eran del partido del Rey [...]". Declaración de Norberto Armijo, ibídem, pág. 162. También: Declaración de José Antonio Santos, Cádiz, 17 de julio de 1819, ibídem, pág. 162. Según los declarantes las normas del Ejército expedicionario determinaban que no se podía comisionar a los componentes de la Compañía de preferencia fuera de la misma. Respecto a la salida forzada del batallón de algunos de sus componentes: Declaración del sargento segundo Benito Brunet, Cádiz, 17 de julio de 1819, ibídem, pág. 164. Declaración de Andrés García, ibídem. pág. 166. Declaración de Juan Velasco, ibídem, pág. 167. Declaración de Baltasar Muñoz, ibidem, pág. 168. 
cación del conde de La Bisbal. Era ridículo elevar un parte por conducto regular, que hubiese sido interceptado por Quiroga y en definitiva, llegaría al General en Jefe. En otro caso, si decidían alertar ellos mismos a la Corte, tendrían que viajar hasta Madrid y encontraban que La Bisbal aislaba el territorio bajo su mando mediante patrullas militares que permanentemente vigilaban los caminos. Establecían los llamados «cordones de sanidad» y todo militar que se encontrase fuera del lugar de su destino debía llevar consigo la autorización o pasaporte correspondiente ${ }^{14}$.

Finalmente, el día 30 de junio, a las nueve de la noche, pusieron el asunto en conocimiento del Juez Civil de Cádiz, en quien confiaba uno de ellos, que ejercía también de Corregidor interino. Le adelantaron «que varios jefes y oficiales subalternos proyectaban una conspiración para no realizar la expedición, que no sabían quienes eran y pensaban que les pudiesen sorprender». El Juez les pidió la delación por escrito para poder actuar. También les presentó a su hermano, un brigadier de marina, que aconsejó poner al corriente al Capitán General del Departamento de Cádiz Baltasar Hidalgo de Cisneros. Por último, concertaron seguir atentos a lo que ocurriese e intentar atraer partidarios con los que oponerse a los conjurados ${ }^{15}$.

El día 1 de julio, también por la noche, Carreras y Santos llevaron al Juez Civil la delación por escrito a falta de firma por si era interceptada. En ella referían las intenciones de los conspiradores, además de las mencionadas en otro apartacio, apoderarse del navío Asia cuando llegase a puerto para disponer de los caudales que traía de América y publicar la Constitución con varios capítulos adicionales ${ }^{16}$.

14 El pasaporte era la autorización expresa que se debía solicitar y obtener, para que un militar sólo o una unidad, pudiesen trasladarse de un lugar a otro, así se les mantenía controlados. Sobre la concesión y uso de pasaportes hay varios ejemplos, como el del coronel Bartolomé Gutiérrez que en una de las últimas entrevistas con el conde de La Bisbal le pidió que le concediese algunas pagas y le diese pasaporte para regresar a Pamplona, donde estaba su destino. Aquel le concedió tres pagas pero no el pasaporte, porque pensó que pretendía engañario, pensando arrestarlo con los otros jefes que conocía implicados en la conjura. Ibídem, Dictamen del fiscal de la causa del Palmar sobre la certificación del conde de La Bisbal, dicha declaración se encuentra en: Legajo 10, Cuaderno 1.\%, folio 261.

15 Había patrullas o destacamentos que vigilaban los caminos y lugares de paso: «[...] que djjere a los Sargentos en la rueda para que estos lo hiciesen saber a sus Compañías, que el citado destacamento era para relevar las tropas que los Cuerpos del Ejercito tenían en el cordón de sanidad [...]". Declaración de Santos San Miguel, Cádiz, Castillo de San Sebastián, 30 de agosto de 1819, ibídem, Legajo 10, Cuaderno 2. ${ }^{\circ}$, folio 91 . Respecto a la denuncia de los dos oficiales: $D e-$ claración del Juez Civil de Cádiz, 14 de agosto de 1819, ibidem, Legajo 11, Sumaria separada contra el sargento primero José Cortat, pág. 37.

16 Respecto al asunto de la constitución, la información se obtuvo de un individuo de tropa quien, evidentemente, tendría un conocimiento muy limitado sobre textos constitucionales, asi que, la información la debió obtener de Quiroga. También es conocido el disgusto de algunos 
El día 2 de julio, nada más abrirse las puertas de Cádiz, el Juez Civil salió hacia San Fernando para entrevistarse con Hidalgo de Cisneros e informarle del asunto. Una vez enterado el Capitán General de Marina, decidieron poner la cuestión en conocimiento del rey lo antes posible. El juez lo haría a través del ministro de Gracia y Justicia Lozano de Torres e Hidalgo de Cisneros directamente al monarca. Se doblaba el canal de transmisión para asegurar que la noticia llegase a su destino. De esta manera, siete días antes del 9 de julio, en que el conde de La Bisbal informó que había extinguido la "proyectada sublevación contra el embarque del Ejército», salía la noticia sobre la existencia y avanzado estado de la conspiración hacia Madrid. Probablemente, sobre el 4 ó 5 de julio llegaría al rey y el día 6 de julio, como es sabido, se tomó la decisión de llamar a ambos capitanes generales, el de Marina y el de Andalucía, a la Corte ${ }^{17}$.

\section{EL PRONUNCIAMIENTO, LA REPRESIÓN Y SUS CONSECUENCIAS}

El conde de La Bisbal, desde marzo de 1819 aproximadamente, permitía que la conspiración se extendiese dentro del Ejército e incluso que se captasen adeptos en su nombre. Así fue posible que pasaran a formar parte de la misma, rápidamente, la mayor parte de los oficiales y gran cantidad de tropa. Después, sobre finales de mayo, comenzó a dudar del proyecto. $Y$, seguramente a finales de junio, estaba decidido a evitar la sublevación.

conspiradores, cuando Riego proclamó, precisamente, la Constitución de 1812. Esta referencia quizás tenga alguna relación con el estudio que se encuentra realizando Claude Morange, aunque en los documentos que he visto, sólo me apareció en una ocasión la alusión a un texto diferente. La Constitución de 1812 se nombra en ellos, una veces, explícitamente, y cuando no es así, el contexto hace pensar que se referian a la misma, pues era el único referente constitucional que había funcionado con anterioridad En todo caso, convendrá hacer un repaso de los documentos. Contestación a los fiscales del Juez civil de Cádiz, 14 de agosto de 1819, ibídem, pág. 37, Y, Vid. Morange, Claude, El programa político de la Conspiración de 1819, Trienio, n. ${ }^{\circ} 39$, Mayo 2002, págs. 31-46.

${ }_{17}$ Sin que se haya dado más información, la denuncia de los dos oficiales era conocida: «La conspiración de O'Dónnell comenzaba a ser crítica de resultas de su postura ambigua, denunciada por ciertos oficiales a la Corte» y «El 6 de julio, a medio día, se reunieron en la casa de Lozano de Torres el ministro de la Guerra y Ugarte, quienes, noticiosos del contenido de la delación y tras larga deliberación, enviaron un correo al conde — de la Bisbal-y al jefe de la escuadra - Hidalgo de Cisneros - para que dejando el mando a sus segundos pasasen a recibir instrucciones a la Corte». Artola, o. c., pág. 504. Al final de párrafo de la primera cita, una nota remite a: E. Ortiz de la Torre, «Papeles de Ugarte» en Bol. Bib. Menéndez Pelayo, 1934, págs. 13-19. La orden quedó sin efecto pues llegó con posterioridad a la represión del Palmar. 
Los motivos que le llevaron a tomar tal decisión probablemente fueron varios. El primero, que era tal la cantidad de rumores subversivos que corrían por la zona de Cádiz y las manifestaciones públicas de oposición al embarque de la tropa, que se vio obligado a ponerlo en conocimiento del rey. Así aparentaba que mantenía el control de la situación y no ponía en peligro su propia credibilidad. El segundo, que recién llegado el mariscal de campo Sarsfield para tomar el mando de una división, a finales de mayo, los conspiradores intentaron atraerlo a la sublevación. Sospechaban de la inactividad del conde de La Bisbal y querían tener un general de recambio. Y Sarsfield, ladinamente, dio parte a su superior a la vez que contemporizaba con los conjurados, pero además, formó un partido y una fuerza contrarrevolucionaria para oponerse a los rebeldes. Pudieron existir otros motivos de carácter político, pero éstos se escapan a lo que se propone en este trabajo y están aún por concretar ${ }^{18}$.

Por su parte, los conjurados tenían todo preparado para pronunciarse a principios de julio. La mayoría de cuerpos rebeldes estaban concentrados en el Puerto de Santa María. Otros dispuestos en el camino a la Isla de León o cubriendo el paso de Sancti Petri. Además, el 1 de julio se dio una orden general en el cantón del Puerto, por la que las unidades deberían estar preparadas para reunirse con sus equipos y armamento en cualquier momento del día. Debido a ella, todos los cuerpos estaban listos para marchar con sus bagajes, lo más engorroso de recoger, en los carros que los tenían que transportar ${ }^{19}$. Más concretamente, en el batallón de Guías tenían preparadas las mochilas y el equipo de campaña y estaban alertados y listos para comenzar a marchar sin pérdida de tiempo ${ }^{20}$.

18 Según Morange, existe un proyecto constitucional creado para ser impuesto tras el pronunciamiento del 8 de julio de 1819. Esta aportación, unida a los datos que se exponen en mis trabajos, permite deducir, que el programa político de los conspiradores no era único. Lo que sí parece claro es que el programa de la mayoría de los militares del Ejército y el que querían imponer era el definido en la Constitución de 1812. Respecto a las informaciones sobre la situación en el Ejército, que mandó el conde de La Bisbal al rey, el ministro de la Guerra Alós confirmó que ha. bían tenido lugar el 28 de mayo, 7 y 8 de junio y 2 y 6 de julio. Comunicación del ministro de la Guerra a los fiscales, 4 de septiembre de 1.819, AGM, Sección 9. ${ }^{\circ}$, Legajo 10, Cuaderno 2. , folio 310. Sobre el intento de atracción de Sarsfield por los conjurados: «[...] a pocos días les acompañó a hacerme una visita un paisano [...] de parte de algunos habitantes de Cádiz [...] y rogarme que cooperase en favor de sus designios dirigidos a remover el sistema actual de Gobierno y restablecer nuevamente las Cortes y Constitución". Carta del mariscal de campo Sarsfield al conde de La Bisbal, Jerez de la Frontera, 24 de junio de 1819, ibídem, Cuaderno 1. ${ }^{\circ}$, folio 65.

19 Declaración del capitán Ramón María de Labra, Ibídem, Cuaderno 2. ', folio 124.

20 Según los sargentos primeros de este batallón: «después de haber pasado lista... a sus respectivas compañías y acudiendo a dar parte al ayudante D. Baltasar Pecman, les previno éste que advirtiesen a los individuos de las suyas tuviesen la mayor vigilancia y estuvieran prontos para formar al primer aviso, teniendo sus mochilas puestas, lo mismo que previnieron a sus com- 
Su objetivo era tomar el citado paso de Sancti Petri, el arsenal de la Carraca y Cádiz. Conseguido éste, se forzaría al rey a reinstaurar la Constitución, para lo que se habían tomado otras medidas. La ocasión para iniciar el pronunciamiento sobrevino cuando se produjo un gran descontento entre la tropa ante el próximo embarque de tres mil hombres ${ }^{21}$. Un importante conjurado, el marqués de Campo Verde, fue a Cádiz sobre el día 28, para tratar seguramente de este asunto con el conde de La Bisbal. No se conoce lo que se trató en la entrevista, pero sí sus consecuencias: los conjurados decidieron el día 4 de julio asesinar al conde si se retiraba del proyecto ${ }^{22}$.

Pocos días después, éste pretendió dispersar la concentración de unidades del Puerto. Antes de que aquello ocurriera, los conjurados decidieron tomar sus objetivos la noche del 6 de julio. Estaban dispuestos a ponerse en marcha cuando, en una junta, Sarsfield les convenció para que esperasen al General en Jefe, con falsas promesas. Este tiempo fue vital, porque permitió a los dos generales preparar la represión ${ }^{23}$.

El día 7 de julio, el conde de la Bisbal dejó asegurada Cádiz, esparció rumores a favor del restablecimiento constitucional, para enmascarar sus verdaderas intenciones, pidió apoyo a Sarsfield y al Capitán General del Departamento de Marina y por la tarde salió con cuatro batallones hacía el

pañías::; el día 6 lo volvió a repetir, "que al primer golpe de generala había de estar el Batallón formado". El Ayudante Baltasar Pecman negó que diese tal orden, por encontrarse enfermo, y que no recuerda quien le sustituyó como ayudante. Contestación de Baltasar Pecman, ibídem, Legajo 11 , Cuaderno $5 .^{\circ}$, folio 66 .

21 El Teniente de Rey de Cádiz advirtió al conde de La Bisbal sobre los rumores «[...] que corrían en esta Plaza, respecto a que no querían embarcarse los Cuerpos destinados a Ultramar [...]". Respuesta del Teniente de Rey de Cádiz a los fiscales, Cádiz, 9 de septiembre de 1819, Ibidem, Legajo 10, Cuaderno 2. , folio 222. También, el Juez Civil «[...] supo que se hablaba en cafés y parajes públicos del disgusto que tenia la tropa en embarcarse y que podría dar lugar a alboroto [...]". Oficio del Juez Civil de Cádiz a los fiscales, 26 de septiembre de 1819, ibídem, folio 338. Los cuerpos rebeldes eran: en el Puerto de Santa María los batallones de infantería Canarias, Soria, Valencia, primero y segundo de Aragón, primero de Cataluña, Asturias y Guías del General, además de la Brigada de Artillería a pie; en Puerto Real el Escuadrón de Artillería; y en el paso de Sancti Petri el batallón segundo de Cataluña.

22 Respecto a la visita de Campo Verde a La Bisbal: Cartas del mariscal de campo Pedro Sarsfield al conde de La Bisbal, Jerez de la Frontera, 4 de julio de 1819, AGM, Sección 9. ${ }^{a}$, Legajo 10 , Cuaderno $1 . \circ$, folio 72 . Respecto a la muerte de La Bisbal: Grases y Gutiérrez «me aseguraron que hubo juntas y [...] se decretó [...] la muerte del conde de La Bisbal [...] el ejecutor un oficial de su propia Guardia [...]». Certificación del general Sarsfield, Jerez de la Frontera, 20 de julio de 1819, ibidem, folio 99.

${ }_{23}$ Sobre la dispersión de los cuerpos del Puerto: Órdenes de cambio de cantón para la caballería y los cuerpos del Puerto de Santa María, ibídem, Cuaderno 2. ${ }^{\circ}$, folio 62 . Respecto a la junta mencionada: Parte del mariscal de campo Pedro Sarsfield al teniente general Enrique José O’Dónnell, Jerez de la Frontera, 16 de julio de 1819, ibídem, folio 46 y siguientes. 
Puerto de Santa María para someter a los rebeldes. Obtuvo la absoluta fidelidad de la tropa tras prometer a los soldados que les eximía de embarcar a América. Sarsfield hizo lo propio con dos regimientos de caballería que tuvo dispuestos para cargar frente al campamento de los sublevados en la madrugada del 7 al 8 . Estos, más fieles al rey, necesitaron un incentivo menor para participar en la represión y sólo se prometió a los sargentos el premio de un grado más ${ }^{24}$.

Los rebeldes habían pasado aquel día ultimando los preparativos del levantamiento. Por la tarde se dieron las instrucciones para el día siguiente. Poco después se preparó a la tropa moral y materialmente. En el regimiento de Aragón se difundió una petición que se había hecho, por la que se quitarían las notas negativas de los expedientes personales, para no limitar la carrera a la tropa y se les recordó que estaban bien mantenidos y equipados gracias a los desvelos del General en Jefe, que teóricamente seguía al frente. En el batallón de Soria se hizo un reparto de dinero la tarde del 7 .

En la madrugada del 7 al 8 de julio, los cuerpos comenzaron a marchar hacía el campo de instrucción del Palmar, donde debían concentrarse. Sobre las cuatro salió del pueblo uno de los batallones y media hora más tarde, desde el campamento de la Victoria, el resto. Ya debían conocer que la caballería del Puerto se había puesto en movimiento y desfilaron para adoptar una línea defensiva por si era necesaria. Sabían además que el conde de La Bisbal se dirigía hacia allí con la guarnición de Cádiz, pero no estaban seguros de sus intenciones. Cuando los batallones ocupaban su puesto en la línea, Sarsfield, que fue el primero en llegar, les mandó detenerse bajo la amenaza de realizar una carga con la caballería. Al poco tiempo, vieron aproximarse por la retaguardia al conde de La Bisbal. Los jefes de los cuerpos del Palmar notaron que todo estaba perdido, adoptaron una coartada que les serviría de defensa y se resignaron con la prisión donde les mandó el conde de La Bisbal. Confiaban en que pudiese haber una próxima ocasión, lo que posibilitaron con su actitud ${ }^{25}$.

24 Sobre las medidas tomadas para asegurar Cádiz: Contestación del teniente de rey de Cádiz a un oficio de los fiscales, 8 de septiembre de 1819 , ibídem, folio 208. Sobre el bulo respecto a la Constitución que hizo correr el conde de La Bisbal: Carta del Coronel Arco Agüero al Mariscal de Campo Sarsfield, Puerto de Santa María, 8 de julio de 1819, ibidem, folio 120. Respecto a la salida de los batallones de Cádiz: Contestación del interrogatorio de los fiscales del teniente coronel Cayetano Bola, 26 de marzo de 1828, ibidem, Legajo 11, Cuaderno 4. ${ }^{\circ}$, folios 898 a 904. Sobre la situación y actitud de la caballería en la mañana del 7 al 8 de julio: Respuesta al interrogatorio del coronel José González Anleo, ibídem, Legajo 10, Cuaderno 2. ${ }^{\circ}$, folio 206.

25 Para mantener la moral de la tropa se les informó de los beneficios que obtendrían en su carrera. Declaración del ayudante Lorenzo García, ibidem, Cuaderno 1. , folio 395, y, Declaración del brigadier $O^{\prime}$ Daly, 13 de septiembre de 1819 , ibidem, Cuaderno $2^{\circ}$, folio 131 . También, se 
Tras lo expuesto, se ha dado a conocer cómo se extendió la trama conspirativa dentro de los batallones del Ejército expedicionario. Quiénes fueron sus agentes y quiénes se opusieron en primera instancia, así como los motivos que tuvieron las distintas clases que lo componían para sublevarse. Además, se ha explicado cómo se realizó y las circunstancias que rodearon la conocida denuncia de los dos oficiales, que provocó la inútil llamada de los dos capitanes generales a Madrid. Con ello, se pretende llenar un corto periodo de once días, cuyo acontecer se ha vivido dentro del Ejército destinado a Ultramar, precisamente, en las fechas próximas a su primer intento de pronunciamiento.

sabe hubo distribución de dinero en uno de los batallones: Declaración del teniente Joaquín Cagigós, ibídem, Cuaderno $1 .{ }^{\circ}$, folio 131 . Sobre las órdenes dadas para la madrugada del día $8 \mathrm{de}$ julio: Contestación del general Mourgeon a los fiscales, 30 de agosto de 1819, ibídem, Cuaderno $2 .^{\circ}$, folio 114. Sobre las noticias que tenían los conjurados del Puerto sobre las acciones en Cádiz del conde de La Bisbal: Declaración del teniente coronel Cayetano Bola, Ibídem, Legajo 11, Cuaderno 4 , folio 898 . 